\title{
COMMENTARY
}

\section{Another step for noninvasive ventilation in chronic obstructive pulmonary disease patients!}

\author{
Samir Jaber* and Gerald Chanques \\ See related research by Scala et al., http://ccforum.com/content/14/2/R80
}

\begin{abstract}
The use of noninvasive positive pressure ventilation (NPPV) in chronic obstructive pulmonary disease (COPD) patients who are not eligible for the technique because of their incapability to spontaneously eliminate accumulated secretions associated with hypercapnic encephalopathy is not recommended and is often considered a contraindication. In a case-control study, an experienced team reported the feasibility and safety of the use of NPPV with early fibreoptic bronchoscopy in selected acutely decompensated COPD patients with hypercapnic encephalopathy, and reported the patients' inability to spontaneously clear copious secretions. The reported data suggest that this innovative therapeutic may be considered as a potential alternative to endotracheal intubation.
\end{abstract}

For patients with an exacerbation of chronic obstructive pulmonary disease (COPD), noninvasive positive pressure ventilation (NPPV) is considered the standard of care [1] and should be available as first-line therapy in any institution that treats acutely ill COPD patients [2]. Most randomised control trials of NPPV for acute respiratory failure, however, have excluded patients without efficient clearance of secretions [2]. As a matter of a fact, the inability to spontaneously remove respiratory secretions has been considered a relative contraindication to applied NPPV in acute respiratory failure, especially if the inability occurs in patients with impaired consciousness and depressed cough $[2,3]$.

Few studies have shown that, within expert units, NPPV is feasible and may be applied with success in

*Correspondence: s-jaber@chu-montpellier.fr

Intensive Care Unit, Anesthesia and Critical Care Department B, Saint Eloi Teaching Hospital, INSERM ERI-25, Université Montpellier 1, Centre Hospitalier Universitaire Montpellier, Montpellier F-34000, France moderate to severe hypercapnic encephalopathy due to COPD $[4,5]$. Diagnostic or therapeutic flexible fibreoptic bronchoscopy (FBO) is often necessary in severely ill patients, especially in hypoxemic and/or COPD patients. Studies have reported that NPPV may be helpful in performing a diagnostic FBO with bronchoalveolar lavage for suspected pneumonia [6,7]. Limited data exist, however, supporting the use of NPPV in COPD patients who are not eligible for the technique because of their incapability to spontaneously eliminate accumulated secretions associated with hypercapnic encephalopathy.

In the previous issue of Critical Care, Scala and colleagues provide data that support the use of NPPV with early FBO performed by an experienced team in acutely decompensated COPD patients with hypercapnic encephalopathy and an inability to spontaneously clear copious secretions [1]. They suggested safety and effectiveness of this strategy including early therapeutic FBO during NPPV performed by an experienced team [1].

The authors performed a 12-month, prospective, matched case-control study including 15 decompensated COPD patients with copious secretion retention and hypercapnic encephalopathy due to community-acquired pneumonia who were undergoing NPPV and 15 controls intubated and receiving conventional mechanical ventilation [1]. They showed that the early suction of secretions with FBO may increase the chance of NPPV success (12 out of 15 patients avoided intubation) and that the method may be considered a potential alternative option to endotracheal intubation Interestingly, this innovative strategy including NPPV was not associated with major adverse events, such as complications related to a delayed (re)emergent intubation, cardiovascular events and pneumothorax. Improvement in arterial blood gases was similar in the two groups. This new approach reduces the rate of tracheostomy and the nosocomial infections associated with endotracheal intubation in comparison with a group of COPD patients treated with invasive mechanical ventilation. These data should be interpreted with caution, however, as the study was not powered for assessing the differences in the rate of tracheostomy and nosocomial infections between the groups. The hospital 
mortality, duration of hospitalisation and duration of ventilation were similar in the two groups.

Despite the great interest of these findings for all practicing clinicians, the present study is a case-control design using observational data and a lack of randomisation [1], which may bias results in favour of the treatment under investigation. Moreover, the two groups were treated in two different units: the patients in the NPPV group were treated in a centre with important expertise and experience in the field of NPPV and FBO techniques, and the patients in the control group (intubated and controlled ventilation) were treated in another unit with less experience - hence limiting the generalisability of the conclusions, as indicated by the authors themselves. This difference may bias results in favour of the new strategy using NPPV with FBO under investigation. The findings may thus not be reproducible in units less experienced in NPPV. Criticism may be also directed towards the choice of the control group including patients treated initially with invasive ventilation who had not previously received NPPV. One could argue that a comparison between NPPV plus FBO and NPPV alone may have been a more appropriate design to address the clinical outcomes of the study.

Larger randomised controlled studies are necessary to confirm these preliminary encouraging results. Especially, at least one trial, performed in a single centre, comparing NPPV combined or not with FBO in less severe COPD decompensated patients with impaired mucous clearance could be of help to integrate with the findings of the present study.

As NPPV is a harmful therapeutic in hypoxemic patients, especially in COPD patients, even when it is used in the best and optimal conditions by a skilled team $[2,3]$, it can be unsafe if used in nonoptimal conditions. It is mandatory that the more severe patients treated by NPPV (with or without FBO) should be closely monitored in an intensive care unit setting and, if there is no improvement in gas exchange or vital signs within the first 1 to 2 hours, intubation should be planned with no delay in the best conditions [8].

In conclusion, extending the indication of NPPV use is always challenging and exciting. It is unfortunate that the preliminary successes of the Scala and colleagues study [1] have yet to be followed up, but future studies should consider the potential risk-benefit ratio of such a strategy (NPPV combined with FBO in COPD with hypercapnic encephalopathy) in the most challenging patients.

\section{Abbreviations}

COPD, chronic obstructive pulmonary disease; FBO, fibreoptic bronchoscopy; NPPV, noninvasive positive pressure ventilation.

\section{Competing interests}

The authors declare that they have no competing interests.

Published: 9 June 2010

\section{References}

1. Scala R, Naldi M, Maccari U: Early fiberoptic bronchoscopy during noninvasive ventilation in patients with decompensated chronic obstructive pulmonary disease due to community-acquired-pneumonia. Crit Care 2010, 14:R80.

2. Robert D, Argaud L: Clinical review: long-term noninvasive ventilation. Crit Care 2007, 11:210.

3. Evans TW: International Consensus Conferences in Intensive Care Medicine: non-invasive positive pressure ventilation in acute respiratory failure. Organised jointly by the American Thoracic Society, the European Respiratory Society, the European Society of Intensive Care Medicine, and the Societe de Reanimation de Langue Francaise, and approved by the ATS Board of Directors, December 2000. Intensive Care Med 2001, 27:166-178.

4. Diaz GG, Alcaraz AC, Talavera JC, Perez PJ, Rodriguez AE, Cordoba FG, Hill NS: Noninvasive positive-pressure ventilation to treat hypercapnic coma secondary to respiratory failure. Chest 2005, 127:952-960.

5. Scala R, Naldi M, Archinucci I, Coniglio G, Nava S: Noninvasive positive pressure ventilation in patients with acute exacerbations of COPD and varying levels of consciousness. Chest 2005, 128:1657-1666.

6. Antonelli M, Conti G, Rocco M, Arcangeli A, Cavaliere F, Proietti R, Meduri GU: Noninvasive positive-pressure ventilation vs. conventional oxygen supplementation in hypoxemic patients undergoing diagnostic bronchoscopy. Chest 2002, 121:1149-1154.

7. Maitre B, Jaber S, Maggiore SM, Bergot E, Richard JC, Bakthiari H, Housset B, Boussignac $G$, Brochard L: Continuous positive airway pressure during fiberoptic bronchoscopy in hypoxemic patients. A randomized double-blind study using a new device. Am J Respir Crit Care Med 2000, 162(3 Pt 1):1063-1067.

8. Jaber S, Jung B, Corne P, Sebbane M, Muller L, Chanques G, Verzilli D, Jonquet $\mathrm{O}$, Eledjam JJ, Lefrant JY: An intervention to decrease complications related to endotracheal intubation in the intensive care unit: a prospective, multiple-center study. Intensive Care Med 2009, 36:248-255.

doi:10.1186/cc9023

Cite this article as: Jaber S, Chanques G: Another step for noninvasive ventilation in chronic obstructive pulmonary disease patients! Critical Care 2010, 14:163. 